\title{
Racial and Gender Differences in Arteriovenous Fistula Use among Incident Hemodialysis Patients
}

\author{
Haimanot Wasse ${ }^{a, b}$ Sari D. Hopson ${ }^{b}$ William McClellan ${ }^{a, b}$ \\ ${ }^{a}$ Renal Division, School of Medicine, and ${ }^{b}$ Rollins School of Public Health, Emory University, Atlanta, Ga., USA
}

\section{Key Words}

Adequacy of care $\cdot$ Chronic kidney disease $\cdot$ Vascular access

\begin{abstract}
Background: Arteriovenous fistula (AVF) use is reported to differ among racial and gender groups. We sought to identify risk factors associated with incident AVF and whether racial and gender differences in AVF use persist after controlling for these factors. Methods: We evaluated 28,712 incident adult hemodialysis patients (age $\geq 18$ ) from five ESRD networks starting dialysis between June 1, 2005 and May 31, 2006. Data were obtained from the Center for Medicaid and Medicare Services 2728 form. Results: Incident AVF use was reported for $11 \%$ of black and $12 \%$ of white patients [OR = 0.89 (95\% Cl: $0.83,0.96)]$, and for $9 \%$ of females and $13 \%$ of males $[\mathrm{OR}=0.66(0.62-0.71)]$. After adjusting for facility clustering, blacks were as likely as whites to use an AVF [OR $=1.00$ (0.92-1.09)], while gender differences persisted [OR $=0.64$ (0.59-0.69)]. Compared to patients with no renal care prior to dialysis initiation, incident AVF use was 16 -fold greater among those with $\geq 12$ months of nephrology care [OR = 15.99 (13.25-19.29)], 9-fold greater among those with 6-12 months of care $[O R=9.00(7.45-10.88)]$ and 7-fold greater among those with at least 6 months of care [OR $=7.13$ (5.738.88)]. Conclusion: Racial, but not gender, differences in incident AVF use were eliminated after accounting for clustering within facilities.

Copyright $\odot 2010$ S. Karger AG, Basel
\end{abstract}

\section{Introduction}

An arteriovenous fistula (AVF) is the preferred hemodialysis vascular access due to its association with superior health outcomes [1-3]. AVFs have longer patency, decreased risk of infection and thrombosis, better blood flow, and lower risk of morbidity and mortality compared to both arteriovenous grafts (AVG) and central venous catheters [1-9]. Regardless of the noted benefits, the prevalence of AVF use in US patients beginning hemodialysis therapy is low and has been reported to be lower among black and female patients compared to white and male patients, respectively $[5,10-12]$.

The reasons for the low prevalence and differences in AVF use are poorly understood. Demographic factors, individual health status, health insurance, pre-ESRD care and geographic location may be associated with the prevalence of AVF use among incident hemodialysis patients and contribute to differences in AVF use [10, 11, 13-16]. The effect of these factors on the prevalence of AVF use and differences in AVF use among incident hemodialysis patients is not well documented.

Few studies have evaluated factors related to AVF use among incident US hemodialysis patients in large cohorts $[10,13,14,16]$. To our knowledge, no study has assessed factors associated with racial and gender differences in AVF use among incident hemodialysis patients. The purpose of this report is to extend observations on the asso-

\section{KARGER}

두 2010 S. Karger AG, Basel

Fax +41613061234 E-Mail karger@karger.ch www.karger.com
Haimanot Wasse, MD, MPH

Emory University, Renal Division, Woodruff Memorial Building, Room 338 1630 Pierce Drive

Atlanta, GA 30322 (USA)

Tel. +1 404727 1598, E-Mail hwasse@emory.edu 
ciation of both modifiable and non-modifiable factors on AVF use among incident ESRD patients in the United States and to describe the impact of these factors on racial and gender differences in AVF use in a population-based cohort of dialysis patients.

\section{Methods}

\section{Study Population}

The study population included black and white adult (aged $\geq 18$ years) patients who initiated hemodialysis therapy between June 1, 2005 and May 31, 2006 at US dialysis facilities in ESRD Network 5 (District of Columbia, Maryland, Virginia and West Virginia), Network 6 (Georgia, North Carolina and South Carolina), Network 8 (Alabama, Mississippi and Tennessee), Network 11 (North Dakota, South Dakota, Minnesota, Wisconsin and Michigan) and Network 13 (Arkansas, Louisiana and Oklahoma).

\section{Data Collection}

De-identified patient information for this study was obtained from the Center for Medicaid and Medicare Services (CMS) 2728 form (End-Stage Renal Disease Medical Evidence Report, Medicare Entitlement and/or Patient Registration) during the years 2005 and 2006. The 2728 form is collected from all incident ESRD patients and is completed by the attending physician, head nurse or social worker at the treatment center where a patient initiates treatment. The 2728 form includes information about patient age, gender, race, weight and height, employment and health insurance status, functional status, comorbid conditions, disability status, pre-ESRD care variables (including nephrology), vascular access used at first outpatient dialysis, and laboratory test values (most recent results within 45 days of first dialysis for serum creatinine, albumin and hemoglobin).

\section{Demographic and Health Characteristics}

Demographic and health characteristics used in our analysis included race (black, white), gender, age, BMI, diabetes reported as the primary cause of ESRD, diabetes as a comorbid condition not indicated as the underlying cause of ESRD, other selected comorbid conditions and disability status. BMI was calculated as weight $(\mathrm{kg}) /$ height $(\mathrm{m})^{2}$ and classified according to the World Health Organization as underweight (BMI <18.5), normal (BMI 18.5 to $<25$ ), overweight (BMI 25 to $<30$ ), obese (BMI 30 to $<40$ ) and very obese (BMI $\geq 40)$ [17]. Selected comorbid conditions included congestive heart failure, atherosclerotic heart disease, peripheral vascular disease, amputation and tobacco use (current smoker). Patients with missing comorbid information were classified as not having the condition. Disability status variables included: inability to ambulate, inability to transfer, needs assistance with daily activities and residence in a nursing home.

\section{Socio-Economic Factors}

Prior employment status was categorized into three categories: unemployed, employed/homemaker/student, and retired due to age or preference/retired due to disability/medical leave of absence from the 2728 form. Health insurance status at dialysis initiation was categorized as uninsured and insured. Individuals were defined as uninsured if their current medical coverage listed on the 2728 form was 'none' and insured if they had any type of insurance reported on the 2728 form.

\section{Pre-ESRD Nephrology Care}

Pre-ESRD nephrology care was assessed from the CMS 2728 form question 'Prior to ESRD therapy: Was patient under care of a nephrologist?' Pre-ESRD nephrology care was categorized as no care, unknown care, less than 6 months, 6-12 months and greater than 12 months.

\section{AVF Use at Initiation of Dialysis}

Incident vascular access use was assessed from the CMS 2728 form questions: 'What access was used on first outpatient dialysis?' and 'Provide vascular access information as to the type of access used (AVF, AVG, catheter (including port device) or other type of access) when the patient first received outpatient dialysis.' Incident patients were defined as using an AVF or other access for first outpatient dialysis.

\section{Statistical Analysis}

Descriptive statistics means, medians and proportions and associations were assessed using $\chi^{2}$ tests and the Mann-Whitney test. Multivariate logistic regression analyses were used to assess the association between AVF use and patient level factors. We sequentially entered demographic, comorbid conditions, disability status, pre-ESRD nephrology, health insurance status and ESRD network in multivariate models to assess factors associated with racial and gender differences in AVF use. Due to multicollinearity in the adjusted models, the variables 'inability to transfer' and 'prior employment status' were removed from the adjusted models. The removal of these variables did not affect the model fit.

We repeated these analyses using generalized estimating equations (GEE) to control for facility clustering effects of AVF use. A small correlation in AVF use was found between the incident patients within the dialysis facility; therefore, we used GEE to analyze outcome variables that have dichotomous correlated responses in order to avoid incorrect inferences. The Genmod procedure in SAS was used to perform the GEE regression analysis, which produced clustered robust standard errors that correct for within-facility correlation of AVF use among patients. All data analyses were performed using SAS version 9.1 software (SAS Inc., Cary, N.C., USA).

\section{Results}

Of 28,918 incident hemodialysis patients, 206 patients were excluded because they were missing initial outpatient vascular access information, leaving 28,712 patients. Of these, 13,113 (45.7\%) were black and 15,599 (54.3\%) were white; 13,303 were females (46.3\%) and 15,409 were males (53.3\%). Incident AVF use was reported among 3,335 incident patients (11.7\%). Black patients were $11 \%$ less likely than whites to use an AVF at dialysis initiation $[\mathrm{OR}=0.89$ (95\% CI: $0.83,0.96)]$ and women were $34 \%$ less likely than men to use an AVF [OR $=0.66(0.62-0.71)]$. Patient characteristics associated with lower incident 
Table 1. Demographic and clinical characteristics of incident hemodialysis patients $(\mathrm{n}=28,712)$

\begin{tabular}{|c|c|c|c|c|c|}
\hline Characteristics & Total & $\begin{array}{l}\text { AVF use (yes) } \\
\mathrm{n}=3,335(11.6 \%)\end{array}$ & $\begin{array}{l}\text { AVF use (no) } \\
\mathrm{n}=25,377(88.4 \%)\end{array}$ & $\begin{array}{l}\text { OR ( } 95 \% \text { CI) AVF } \\
\text { use vs. no AVF use }\end{array}$ & $\mathrm{p}$ value \\
\hline \multicolumn{6}{|l|}{ Race, $n$} \\
\hline Black & $13,113(45.7)$ & $1,440(43.2)$ & $11,673(46.0)$ & $0.89(0.83-0.96)$ & 0.0021 \\
\hline White $^{\mathrm{a}}$ & $15,599(54.0)$ & $1,895(56.8)$ & $13,704(54.0)$ & 1 & \\
\hline \multicolumn{6}{|l|}{ Gender, n } \\
\hline Female & $13,303(46.3)$ & $1,250(37.5)$ & $12,053(47.5)$ & $0.66(0.62-0.71)$ & $<0.0001$ \\
\hline Male $^{\mathrm{a}}$ & $15,409(53.6)$ & $2,085(62.5)$ & $13,324(52.5)$ & 1 & \\
\hline Age, years & $61.9 \pm 15.28$ & $62.08 \pm 13.74$ & $61.87 \pm 15.44$ & - & $0.8362^{\mathrm{b}}$ \\
\hline \multicolumn{6}{|l|}{ Age, $n$} \\
\hline $18-29$ & $862(3.0)$ & $61(1.8)$ & $801(3.2)$ & $0.53(0.4-0.69)$ & $<0.0001$ \\
\hline $30-39$ & $1,716(6.0)$ & $174(5.2)$ & $1,542(6.1)$ & $0.78(0.65-0.92)$ & 0.0043 \\
\hline $40-49$ & $3,484(12.1)$ & $385(11.5)$ & $3,099(12.2)$ & $0.86(0.75-0.97)$ & 0.0175 \\
\hline $50-59$ & $5,757(20.0)$ & $742(22.2)$ & $5,015(19.8)$ & $1.02(0.92-1.13)$ & 0.7175 \\
\hline $60-69^{a}$ & $6,700(23.3)$ & $849(25.5)$ & $5,851(23.1)$ & 1 & \\
\hline $70-79$ & $6,691(23.3)$ & $791(23.7)$ & $5,900(23.2)$ & $0.92(0.83-1.03)$ & 0.1337 \\
\hline $80+$ & $3,502(12.2)$ & $333(10.0)$ & $3,169(12.5)$ & $0.72(0.63-0.83)$ & $<0.0001$ \\
\hline BMI & $28.84 \pm 7.6$ & $29.13 \pm 7.2$ & $28.81 \pm 7.6$ & - & $0.0001^{\mathrm{b}}$ \\
\hline \multicolumn{6}{|l|}{ WHO BMI category, $\mathrm{n}$} \\
\hline Underweight $<18.5$ & $944(3.4)$ & $71(2.2)$ & $873(3.5)$ & $0.67(0.52-0.86)$ & 0.0016 \\
\hline Normal weight $18.5-24.9^{\mathrm{a}}$ & $9,032(32.2)$ & $980(30.0)$ & $8,052(32.4)$ & 1 & \\
\hline Overweight 25-29.9 & $7,822(27.9)$ & $973(29.8)$ & $6,849(27.6)$ & $1.17(1.06-1.28)$ & 0.0013 \\
\hline Obese $30-39.9$ & $7,788(27.7)$ & $964(29.5)$ & $6,824(27.5)$ & $1.16(1.06-1.28)$ & 0.0020 \\
\hline Very obese $\geq 40$ & $2,495(8.9)$ & $281(8.6)$ & $2,214(8.9)$ & $1.04(0.91-1.20)$ & 0.5593 \\
\hline \multicolumn{6}{|l|}{ Diabetes, $\mathrm{n}$} \\
\hline Diabetic ESRD & $12,409(43.2)$ & $1,508(45.2)$ & $10,901(42.96)$ & $1.02(0.95-1.10)$ & 0.5468 \\
\hline Comorbid diabetes & $3,778(13.2)$ & $335(10.1)$ & $3,442(13.6)$ & $0.72(0.64-0.82)$ & \\
\hline No diabetes ${ }^{\mathrm{a}}$ & $12,525(43.6)$ & $1,491(44.7)$ & $11,034(43.5)$ & 1 & $<0.0001$ \\
\hline \multicolumn{6}{|l|}{ Comorbid conditions, $\mathrm{n}$} \\
\hline Reference $=$ no reported disease & $10,129(35.3)$ & $907(27.2)$ & $9,222(36.3)$ & $0.65(0.60-0.71)$ & $<0.0001$ \\
\hline $\mathrm{CHF}$ & $6,316(22.0)$ & $726(21.8)$ & $5,590(22.0)$ & $0.99(0.90-1.08)$ & 0.7346 \\
\hline ASCVD & $4,338(15.1)$ & $494(14.8)$ & $3,844(15.2)$ & $0.97(0.88-1.08)$ & 0.6116 \\
\hline PVD & $1,019(3.6)$ & $76(2.3)$ & $943(3.7)$ & $0.60(0.48-0.77)$ & $<0.0001$ \\
\hline Amputation & $2,380(8.3)$ & $271(8.1)$ & $2,109(8.3)$ & $0.98(0.86-1.11)$ & 0.7160 \\
\hline \multicolumn{6}{|l|}{ Disability (reference $=$ no disability), $\mathrm{n}$} \\
\hline Inability to ambulate & $2,134(7.4)$ & $110(3.3)$ & $2,024(8.0)$ & $0.39(0.32-0.48)$ & $<0.0001$ \\
\hline Inability to transfer & $946(3.3)$ & $37(1.1)$ & $909(3.6)$ & $0.30(0.22-0.42)$ & $<0.0001$ \\
\hline Need assistance with DA & $3,366(11.7)$ & $213(6.4)$ & $3,153(12.4)$ & $0.48(0.42-0.56)$ & $<0.0001$ \\
\hline Nursing home residence & $2,010(7.0)$ & $84(2.5)$ & $1,926(7.6)$ & $0.31(0.25-0.39)$ & $<0.0001$ \\
\hline \multicolumn{6}{|l|}{ Current health insurance, $\mathrm{n}$} \\
\hline Yes & $26,225(91.3)$ & $3,171(95.1)$ & $23,054(90.8)$ & $1.95(1.66-2.29)$ & $<0.0001$ \\
\hline $\mathrm{No}^{\mathrm{a}}$ & $2,486(8.7)$ & $164(4.9)$ & $2,322(9.2)$ & 1 & \\
\hline \multicolumn{6}{|l|}{ Nephrologist care time $e^{c}, \mathrm{n}$} \\
\hline No care ${ }^{\mathrm{a}}$ & $9,600(33.4)$ & $175(5.3)$ & $9,425(37.1)$ & 1 & $<0.0001^{\mathrm{d}}$ \\
\hline$<6$ months & $1,807(6.3)$ & $229(6.9)$ & $1,578(6.2)$ & $7.82(6.37-9.58)$ & \\
\hline $6-12$ months & $7,831(27.3)$ & $1,171(35.1)$ & $6,660(26.2)$ & $9.47(8.05-11.13)$ & \\
\hline$>12$ months & $6,893(24.0)$ & $1,647(49.4)$ & $5,246(20.7)$ & $16.91(14.42-19.83)$ & \\
\hline Unknown or missing & $2,581(9.00)$ & $113(3.4)$ & $2,468(9.7)$ & $2.47(1.94-3.14)$ & \\
\hline \multicolumn{6}{|l|}{ Prior employment status, $\mathrm{n}$} \\
\hline Unemployed & $5,636(19.6)$ & $507(15.2)$ & $5,129(20.2)$ & $0.71(0.63-0.81)$ & $<0.0001$ \\
\hline Employed, homemaker or student ${ }^{\mathrm{a}}$ & $5,962(20.8)$ & $725(21.7)$ & $5,237(20.6)$ & 1 & \\
\hline Retired or MLOA & $16,902(58.9)$ & $2,071(62.1)$ & $14,831(58.4)$ & $1.01(0.92-1.10)$ & 0.8511 \\
\hline Missing & $212(0.7)$ & $32(1.0)$ & $180(0.7)$ & $1.29(0.88-1.89)$ & 0.2008 \\
\hline \multicolumn{6}{|l|}{ ESRD network, n } \\
\hline Network 5 & $5,829(20.3)$ & $576(17.3)$ & $5,253(20.7)$ & $0.73(0.65-0.81)$ & $<0.0001$ \\
\hline Network $6^{\text {a }}$ & $7,748(27.0)$ & $1,018(30.5)$ & $6,730(26.5)$ & 1 & \\
\hline Network 8 & $4,923(17.2)$ & $622(18.6)$ & $4,301(17.0)$ & $0.96(0.86-1.06)$ & 0.4098 \\
\hline Network 11 & $6,401(22.3)$ & $725(21.7)$ & $5,676(22.4)$ & $0.84(0.76-0.94)$ & 0.0011 \\
\hline Network 13 & $3,811(13.3)$ & $394(11.8)$ & $3,417(13.5)$ & $0.76(0.67-0.86)$ & $<0.0001$ \\
\hline
\end{tabular}

Values are expressed as means \pm SD or numbers, with percentages in parentheses. The comorbid diabetes category does not include patients with diabetes as cause of ESRD. DA = Daily activity; MLOA = medical leave of absence; $\mathrm{CHF}=$ congestive heart failure; ASCVD = arteriosclerotic cardiovascular disease; $\mathrm{PVD}=$ peripheral vascular disease; $\mathrm{OR}=$ odds ratio.
${ }^{a}$ Referent category. ${ }^{b}$ Nonparametric Mann-Whitney test (used when continuous variable is not normally distributed). ${ }^{c}$ Subgroup numbers may not add up to total because of missing data. ${ }^{\mathrm{d}} \chi^{2}$ trend test for ordinal variables (missing category is not included in test). 
Table 2. Models assessing the impact of covariates on racial differences in AVF use of incident hemodialysis patients

\begin{tabular}{|c|c|c|c|c|}
\hline Model components & $\begin{array}{l}\text { Non-GEE logistic model } \\
\text { OR ( } 95 \% \text { CI) } \\
\text { black vs. white }\end{array}$ & $\mathrm{p}$ value & $\begin{array}{l}\text { GEE logistic model } \\
\text { POR }(95 \% \mathrm{CI}) \\
\text { black vs. white }\end{array}$ & $\mathrm{p}$ value \\
\hline Unadjusted & $0.89(0.83-0.96)$ & 0.0021 & $0.92(0.85-1.00)$ & 0.0526 \\
\hline Demographics & $0.92(0.85-0.99)$ & 0.0274 & $0.95(0.88-1.03)$ & 0.2448 \\
\hline Comorbid condition and disability & $0.91(0.85-0.99)$ & 0.0190 & $0.94(0.87-1.02)$ & 0.1588 \\
\hline Pre-ESRD nephrology care & $1.00(0.92-1.08)$ & 0.9575 & $1.00(0.92-1.09)$ & 0.9381 \\
\hline Health insurance & $1.01(0.93-1.09)$ & 0.8528 & $1.01(0.93-1.10)$ & 0.7949 \\
\hline ESRD network (region) & $0.98(0.90-1.07)$ & 0.6487 & $1.00(0.92-1.09)$ & 0.9455 \\
\hline
\end{tabular}

Model components only included factors with p value $\leq 0.10$ in the bivariate analyses for both AVF and race. All GEE models account for facility clustering effects.

Demographics $=$ age and gender. Comorbid condition and disability = diabetes as cause of ESRD, BMI, comorbid conditions (congestive heart failure, amputation, diabetes), disabilities (inability to ambulate, needs assistance with daily activities, resides in a nursing home). Health insurance refers to health insurance status at dialysis initiation. ESRD network = Network 5 (District of Columbia, Maryland, Virginia, and West Virginia), Network 6 (Georgia, North and South Carolina), Network 8 (Alabama, Mississippi, Tennessee), Network 11 (North and South Dakota, Minnesota, Wisconsin, Michigan) and Network 13 (Arkansas, Louisiana, Oklahoma). OR = Odds ratio.

Table 3. Models assessing the impact of covariates on gender differences in AVF use of incident hemodialysis patients

\begin{tabular}{|c|c|c|c|c|}
\hline Model components & $\begin{array}{l}\text { Non-GEE logistic model } \\
\text { POR }(95 \% \mathrm{CI}) \\
\text { female vs. male }\end{array}$ & $\mathrm{p}$ value & $\begin{array}{l}\text { GEE logistic model } \\
\text { POR }(95 \% \mathrm{CI}) \\
\text { female vs. male }\end{array}$ & $\mathrm{p}$ value \\
\hline Unadjusted & $0.66(0.62-0.71)$ & $<0.0001$ & $0.68(0.63-0.73)$ & $<0.0001$ \\
\hline Demographics & $0.67(0.62-0.72)$ & $<0.0001$ & $0.68(0.63-0.73)$ & $<0.0001$ \\
\hline Comorbid condition and disability & $0.67(0.62-0.72)$ & $<0.0001$ & $0.68(0.63-0.73)$ & $<0.0001$ \\
\hline Pre-ESRD nephrology care & $0.64(0.59-0.69)$ & $<0.0001$ & $0.64(0.60-0.69)$ & $<0.0001$ \\
\hline Health insurance & $0.63(0.58-0.68)$ & $<0.0001$ & $0.64(0.59-0.69)$ & $<0.0001$ \\
\hline ESRD network (region) & $0.63(0.58-0.68)$ & $<0.0001$ & $0.64(0.59-0.69)$ & $<0.0001$ \\
\hline
\end{tabular}

Model components only included factors with p value $\leq 0.10$ in the bivariate analyses for both AVF and gender. All GEE models account for facility clustering effects.

Demographics = age and race. Comorbid condition and disability = diabetes as cause of ESRD, BMI, comorbid conditions (congestive heart failure, amputation, diabetes), disabilities (inability to ambulate, needs assistance with daily activities, resides in a nursing home). Health insurance refers to health insurance status at dialysis initiation. ESRD network = Network 5 (District of Columbia, Maryland, Virginia, and West Virginia), Network 6 (Georgia, North and South Carolina), Network 8 (Alabama, Mississippi, Tennessee), Network 11 (North and South Dakota, Minnesota, Wisconsin, Michigan) and Network 13 (Arkansas, Louisiana, Oklahoma). OR = Odds ratio.
AVF use included both younger and older age, lower BMI, comorbidity due to diabetes, congestive heart failure and previous amputation. Patients who were reported to have an inability to ambulate or transfer, needed assistance with daily activities, or institutionalized in a nursing home had lower incident AVF use as did patients who were unemployed or who lacked health insurance (table 1).
In contrast, pre-ESRD care was associated with increased incident AVF use (table 1). Increasing number of months of pre-ESRD nephrology care was associated with an increased likelihood of incident AVF use $(\mathrm{p}<$ 0.0001). Compared to patients with no nephrology care, patients with nephrology care for $<6$ months, 6-12 months and $>12$ months were more likely to use an AVF $[\mathrm{OR}=7.82(6.37-9.58), \mathrm{OR}=9.47(8.05-11.13)$ and $\mathrm{OR}=$ 16.91 (14.42-19.83), respectively]. 
Table 4. Logistic model: predictors of AVF use among incident ESRD patients in networks $5,6,8,11$, and $13^{\mathrm{b}}$

\begin{tabular}{|c|c|c|c|}
\hline Patient characteristic & $\begin{array}{l}\text { Adjusted } \\
\text { OR of } \\
\text { AVF use }\end{array}$ & $95 \% \mathrm{CI}$ & $\mathrm{p}$ value \\
\hline \multicolumn{4}{|l|}{ Race } \\
\hline Black & 1.00 & $0.92-1.09$ & 0.9455 \\
\hline White $^{\mathrm{a}}$ & 1 & - & \\
\hline \multicolumn{4}{|l|}{ Gender } \\
\hline Female & 0.64 & $0.59-0.69$ & $<0.0001$ \\
\hline Male $^{\mathrm{a}}$ & 1 & - & \\
\hline \multicolumn{4}{|l|}{ Age } \\
\hline $18-29$ & 0.61 & $0.47-0.80$ & 0.0004 \\
\hline $30-39$ & 0.80 & $0.67-0.96$ & 0.0155 \\
\hline $40-49$ & 0.89 & $0.78-1.01$ & 0.0761 \\
\hline $50-59$ & 1.01 & $0.90-1.13$ & 0.8693 \\
\hline $60-69^{a}$ & 1 & - & - \\
\hline $70-79$ & 0.93 & $0.84-1.04$ & 0.2018 \\
\hline $80+$ & 0.83 & $0.72-0.95$ & 0.0068 \\
\hline \multicolumn{4}{|l|}{ WHO BMI category } \\
\hline Underweight $<18.5$ & 0.74 & $0.57-0.95$ & 0.0198 \\
\hline Normal weight $18.5-24.9^{\mathrm{a}}$ & 1 & - & - \\
\hline Overweight $25-29.9$ & 1.09 & $0.99-1.20$ & 0.0985 \\
\hline Obese $30-39.9$ & 1.06 & $0.95-1.18$ & 0.3045 \\
\hline Very obese $\geq 40$ & 1.03 & $0.89-1.19$ & 0.6978 \\
\hline \multicolumn{4}{|l|}{ Diabetes } \\
\hline Diabetic ESRD & 0.88 & $0.81-0.96$ & 0.0039 \\
\hline Comorbid diabetes & 0.73 & $0.64-0.83$ & $<0.0001$ \\
\hline No diabetes ${ }^{\mathrm{a}}$ & 1 & - & \\
\hline \multicolumn{4}{|c|}{ Comorbid conditions $($ reference $=$ no disease $)$} \\
\hline $\mathrm{CHF}$ & 0.67 & $0.62-0.74$ & $<0.0001$ \\
\hline Amputation & 0.66 & $0.52-0.84$ & 0.0008 \\
\hline \multicolumn{4}{|c|}{ Disability (reference $=$ no disability) } \\
\hline Inability to ambulate & 0.71 & $0.57-0.90$ & 0.0036 \\
\hline Need assistance with DA & 0.75 & $0.63-0.89$ & 0.0009 \\
\hline Nursing home residence & 0.66 & $0.52-0.84$ & 0.0005 \\
\hline \multicolumn{4}{|l|}{ Current health insurance } \\
\hline Yes & 1.39 & $1.15-1.68$ & 0.0007 \\
\hline $\mathrm{No}^{\mathrm{a}}$ & 1 & & \\
\hline \multicolumn{4}{|l|}{ Nephrologist care time } \\
\hline No care & 1 & & \\
\hline$<6$ months & 7.13 & $5.73-8.88$ & $<0.0001$ \\
\hline $6-12$ months & 9.00 & $7.45-10.88$ & $<0.0001$ \\
\hline$>12$ months & 15.99 & $13.25-19.29$ & $<0.0001$ \\
\hline Unknown or missing & 2.43 & $1.86-3.18$ & $<0.0001$ \\
\hline \multicolumn{4}{|l|}{ ESRD network } \\
\hline Network 5 & 0.80 & $0.69-0.92$ & 0.0015 \\
\hline Network $6^{\mathrm{a}}$ & 1 & & \\
\hline Network 8 & 1.09 & $0.94-1.27$ & 0.2515 \\
\hline Network 11 & 0.88 & $0.76-1.01$ & 0.0742 \\
\hline Network 13 & 0.91 & $0.76-1.08$ & 0.2620 \\
\hline
\end{tabular}

${ }^{a}$ Referent category. ${ }^{b}$ GEE model accounted for facility clustering effects and adjusted for race, gender, age, health insurance status at dialysis initiation, pre-ESRD nephrologist care, diabetes as cause of ESRD, BMI, comorbid conditions (CHF, amputation, diabetes), disabilities (inability to ambulate, needs assistance with DA, resides in a nursing home) and ESRD network.

$\mathrm{DA}=$ Daily activity; $\mathrm{CHF}=$ congestive heart failure.
In the multivariate logistic model that did not account for the grouping of incident patients within treatment centers, race persisted as a significant predictor of AVF use after controlling for patient demographics and health status at the initiation of dialysis (table 2). After controlling for demographic characteristics and health status, blacks remained less likely than whites to have an incident AVF [OR $=0.91(0.85-0.99)]$. After further adjustment for pre-ESRD nephrology care, race was no longer associated with incident AVF [OR $=1.00(0.92-1.08)]$ and addition of health insurance, employment status and ESRD regional network did not change the lack of an association between race and AVF. In the GEE logistic model, which controlled for the similarities in AVF use among incident patients at individual treatment centers, the racial difference in AVF use was absent even in the unadjusted model [OR $=0.92(0.85-1.00)]$, and addition of other patient covariates did not change the lack of association between race and AVF (table 2).

In contrast to racial differences in incident AVF use, gender differences persisted in logistic models after accounting for demographic factors, comorbid and disability conditions, pre-ESRD nephrology care, health insurance, and ESRD network. In the fully adjusted model, the OR comparing the odds of AVF use among females to the odds of AVF use among males was 0.63 (0.58-0.68) (table 3). This finding was similar in the GEE logistic models with a fully adjusted OR of $0.64(0.59-0.69)$.

Race-incident AVF interactions in stratified analyses (by age, gender, diabetes as primary cause of ESRD, presence of pre-ESRD care) and multivariable interactions were examined for each covariate. These interaction effects were not significant.

Other patient characteristics independently associated with incident AVF use included age, BMI, diabetes as the cause of ESRD, comorbid diabetes, congestive heart failure, amputation, inability to ambulate, needs assistance with daily activities, residence in a nursing home, health insurance status at dialysis initiation and pre-ESRD nephrology care (table 4). The strongest predictor of AVF use at dialysis initiation was nephrology care prior to ESRD therapy. After controlling for other factors, patients who received nephrology care for more than 12 months before initiating hemodialysis were 16 times more likely to use an AVF [OR $=16.0$ (13.2519.29)] at the start of dialysis than those who did not receive pre-ESRD nephrology care. Patients receiving care 6-12 months prior to dialysis initiation were 9 times more likely to use an AVF than those who did not receive pre-ESRD nephrology care $[\mathrm{OR}=9.0(7.45-$ 
10.88)], while those receiving care $<6$ months prior to dialysis were 7 times more likely to use an AVF than those who did not receive pre-ESRD nephrology care $[\mathrm{OR}=7.1(5.73-8.88)]$.

\section{Discussion}

Our main finding is that racial differences observed in incident AVF use were reduced after accounting for patient demographics and health status, and eliminated when pre-ESRD nephrology care was accounted for in multivariate models. However, these models failed to account for patient similarities in AVF use within individual treatment centers and when this was accounted for, racial differences in incident AVF use were absent before adjusting for other patient characteristics. In contrast to race, gender differences in AVF use persisted after controlling for patient characteristics and accounting for within-center clustering of AVF use.

Previous studies have found variable associations between race, gender and AVF use. Stehman-Breen et al. [14] found that race was not a significant predictor of AVF use, but gender persisted as a predictor of permanent vascular access use in the adjusted model. However, the number of nephrology visits prior to ESRD therapy was the strongest predictor of permanent vascular access use (AVF or AVG vs. catheter) at the start of hemodialysis. Astor et al. [13] found that neither race nor gender were significant predictors of permanent vascular access use, but found that the earlier the referral to a nephrologist, the more likely a permanent vascular access was used at the start of hemodialysis. Port et al. [10] used data from an international study of dialysis patients, DOPPS, and found that male gender, early pre-ESRD nephrology care and not having a surgery trainee perform or assist in placing the permanent access were associated with an increased likelihood of AVF versus AVG use among incident hemodialysis patients. They also found that gender, history of angina, pre-ESRD nephrology care and time from referral for access to access placement were associated with permanent access (AVF or AVG vs. catheter) use among incident patients. Hirth et al. [18] used USRDS data and found that the type of permanent vascular access (AVF vs. AVG) used among incident hemodialysis patients was associated with gender, comorbid conditions, health insurance and geographic region. Our finding of an absence of racial differences in incident AVF use are consistent with these earlier studies and raise the hypothesis that local variations in pre-ESRD nephrology care associated with individual treatment centers may contribute to the small racial differences in incident AVF use, which were noted in our models prior to the adjustment for pre-ESRD nephrology care in the logistic model and within treatment center clustering in the GEE model.

We found that females were $36 \%$ less likely than males to use an AVF at dialysis initiation. Several studies report that females are more likely to use an AVG or central venous catheter than an AVF $[11,12,19,20]$. Vein caliber does not appear to differ by gender, and in two singlecenter studies, there was no gender difference in the likelihood of pre-ESRD vascular access placement [21, 22]. However, females with an AVF experience a greater number of early vascular access-related procedures presumably to promote AVF maturation, and may experience poorer AVF maturation and AVF dysfunction [19, 22-25].

Additional factors which may influence the observed gender differences in incident AVF use include nephrology or surgical bias toward AVG placement in women, patient reluctance to undergo AVF surgery and surgical referral time.

Several limitations of our study should be noted. We are limited to available covariates from the Medicare 2728 form, and therefore lack information on additional factors thought to influence permanent vascular access use, such as nephrologist or surgeon preference for vascular access type or patient participation in decision making. Data misclassification for some of the variables, such as comorbid conditions and pre-ESRD care, may exist due to patient data reporting by ESRD facility staff rather than the patient. A previous study using CMS 2728 data found that comorbid conditions reported on the 2728 form were underreported [26]. The data we used were cross-sectional, so we were only able to assess the prevalence of AVF use among an incident hemodialysis cohort rather than the rate of AVF use over time. By only examining the type of vascular access used at dialysis initiation, we may be overestimating the effect of preESRD nephrology care and other factors on AVF use in the first months of dialysis therapy. We did not have any information on the quality or intensity of care by nephrologists after the patient was referred to them, so we could not assess the effect of nephrology health care practices on AVF use at dialysis initiation. Further, we lack data addressing local practice patterns of AVF creation, provision of pre-dialysis education, and reasons for ESRD network variation in incident AVF use. We did not have any information on the presence of AVFs that 
failed to mature among our patient population, so we were unable to evaluate the impact of this factor on AVF use at dialysis initiation.

While our cohort is limited to five ESRD renal networks, our data has several strengths. The size of our patient cohort is one of the largest studied in the area of hemodialysis vascular access, has significant representation of black patients (45.7\%), and comparable incident AVF use to that reported nationally, allowing for generalization of our results to the US hemodialysis population. This study extends the observation that pre-ESRD nephrology care is strongly associated with AVF use among incident hemodialysis patients. Additionally, this study is one of few to assess the association between patient demographic, health status, health insurance, preESRD care and geographic region on racial and gender differences in AVF use among incident dialysis patients. Finally, we used GEE to adjust for facility clustering effects on AVF use, which produced unbiased robust standard errors.

In summary, patient demographics, health status, pre-ESRD nephrology care and health insurance are associated with incident AVF use, and controlling for these factors accounts for racial, but not gender, differences observed at the start of hemodialysis therapy. Fu- ture studies should assess the role of factors, such as intensity of pre-ESRD care, nephrology practice patterns, patient knowledge of renal replacement therapy, patient knowledge of preferred vascular access type and physician-patient interaction in ESRD preparation activities, in promoting AVF creation and maturation prior to the start of dialysis therapy as well as the effect of these factors on gender differences in AVF use at dialysis initiation. These factors may provide useful avenues of intervention to improve AVF use among incident hemodialysis patients.

\section{Acknowledgements}

This work was supported in part by a National Institutes of Health Career Development Award K23 DK65634 (H.W.). The analyses upon which this publication is based were performed under Contract No. 500-96-P704, entitled 'Operation Utilization and Quality Control Peer Review Organization for the State of Georgia,' sponsored by CMS, Department of Health and Human Services. The conclusions and opinions expressed, and methods used herein are those of the authors. They do not necessarily reflect CMS policy. The authors assume full responsibility for the accuracy and completeness of the ideas presented.

\section{References}

1 Clinical practice guidelines for vascular access. Am J Kidney Dis 2006;48(suppl 1): S248-S273.

2 III. NKF-K/DOQI Clinical Practice Guidelines for Vascular Access: update 2000. Am J Kidney Dis 2001;37(1 Suppl 1):S137-S181.

3 NKF-DOQI clinical practice guidelines for vascular access. National Kidney Foundation-Dialysis Outcomes Quality Initiative. Am J Kidney Dis 1997;30(4 Suppl 3):S150S191.

-4 Rayner HC, Besarab A, Brown WW, Disney A, Saito A, Pisoni RL: Vascular access results from the Dialysis Outcomes and Practice Patterns Study (DOPPS): performance against Kidney Disease Outcomes Quality Initiative (K/DOQI) Clinical Practice Guidelines. Am J Kidney Dis 2004;44(5 Suppl 2):22-26.

5 Astor BC, Eustace JA, Powe NR, Klag MJ, Fink NE, Coresh J: Type of vascular access and survival among incident hemodialysis patients: the Choices for Healthy Outcomes in Caring for ESRD (CHOICE) Study. J Am Soc Nephrol 2005;16:1449-1455.
-6 Lorenzo V, Martn M, Rufino M, Hernandez D, Torres A, Ayus JC: Predialysis nephrologic care and a functioning arteriovenous fistula at entry are associated with better survival in incident hemodialysis patients: an observational cohort study. Am J Kidney Dis 2004;43:999-1007.

7 Xue JL, Dahl D, Ebben JP, Collins AJ: The association of initial hemodialysis access type with mortality outcomes in elderly Medicare ESRD patients. Am J Kidney Dis 2003;42: 1013-1019.

-8 Pastan S, Soucie JM, McClellan WM: Vascular access and increased risk of death among hemodialysis patients. Kidney Int 2002;62: 620-626.

9 Powe NR, Jaar B, Furth SL, Hermann J, Briggs W: Septicemia in dialysis patients: incidence, risk factors, and prognosis. Kidney Int 1999;55:1081-1090.

10 Port FK, Pisoni RL, Bragg-Gresham JL, Satayathum SS, Young EW, Wolfe RA, Held PJ: DOPPS estimates of patient life years attributable to modifiable hemodialysis practices in the United States. Blood Purif 2004;22: $175-180$
-11 Reddan D, Klassen P, Frankenfield DL, Szczech L, Schwab S, Coladonato J, Rocco M, Lowrie EG, Owen WF Jr: National profile of practice patterns for hemodialysis vascular access in the United States. J Am Soc Nephrol 2002;13:2117-2124.

-12 Allon M, Ornt DB, Schwab SJ, Rasmussen C, Delmez JA, Greene T, Kusek JW, Martin AA, Minda S: Factors associated with the prevalence of arteriovenous fistulas in hemodialysis patients in the HEMO study. Hemodialysis (HEMO) Study Group. Kidney Int 2000; 58:2178-2185.

13 Astor BC, Eustace JA, Powe NR, Klag MJ, Sadler JH, Fink NE, Coresh J: Timing of nephrologist referral and arteriovenous access use: the CHOICE Study. Am J Kidney Dis 2001;38:494-501.

14 Stehman-Breen CO, Sherrard DJ, Gillen D, Caps M: Determinants of type and timing of initial permanent hemodialysis vascular access. Kidney Int 2000;57:639-645.

-15 Feldman HI, Joffe M, Rosas SE, Burns JE, Knauss J, Brayman K: Predictors of successful arteriovenous fistula maturation. Am J Kidney Dis 2003;42:1000-1012. 
-16 Avorn J, Winkelmayer WC, Bohn RL, Levin R, Glynn RJ, Levy E, Owen W Jr: Delayed nephrologist referral and inadequate vascular access in patients with advanced chronic kidney failure. J Clin Epidemiol 2002;55: 711-716.

17 WHO Regional Office for Europe Nutrition and Food Security. Body Mass Index (BMI). http://www.euro.who.int/nutrition/ 20030507_1 (accessed November 12, 2006).

18 Hirth RA, Turenne MN, Woods JD, Young EW, Port FK, Pauly MV, Held PJ: Predictors of type of vascular access in hemodialysis patients. JAMA 1996;276:1303-1308.
19 Astor BC, Coresh J, Powe NR, Eustace JA, Klag MJ: Relation between gender and vascular access complications in hemodialysis patients. Am J Kidney Dis 2000;36:11261134.

20 Wasse H, Speckman RA, Frankenfield DL, Rocco MV, McClellan WM: Predictors of delayed transition from central venous catheter use to permanent vascular access among ESRD patients. Am J Kidney Dis 2007;49: 276-283.

21 Lee T, Barker J, Allon M: Associations with predialysis vascular access management. Am J Kidney Dis 2004;43:1008-1013.

-22 Caplin N, Sedlacek M, Teodorescu V, Falk A, Uribarri J: Venous access: women are equal. Am J Kidney Dis 2003;41:429-432.

-23 Miller CD, Robbin ML, Allon M: Gender differences in outcomes of arteriovenous fistulas in hemodialysis patients. Kidney Int 2003;63:346-352.
4 Ernandez T, Saudan P, Berney T, Merminod T, Bednarkiewicz M, Martin PY: Risk factors for early failure of native arteriovenous fistulas. Nephron Clin Pract 2005;101:c39-c44.

25 Miller PE, Tolwani A, Luscy CP, Deierhoi $\mathrm{MH}$, Bailey R, Redden DT, Allon M: Predictors of adequacy of arteriovenous fistulas in hemodialysis patients. Kidney Int 1999;56: 275-280.

26 Longenecker JC, Coresh J, Klag MJ, Levey AS, Martin AA, Fink NE, Powe NR: Validation of comorbid conditions on the endstage renal disease medical evidence report: the CHOICE study. Choices for Healthy Outcomes in Caring for ESRD. J Am Soc Nephrol 2000;11:520-529. 